an example, we may mention the case of the strongest vibration line in the spectrum of liquid carbon disulphide. Careful measurements, using a pointolite mercury lamp and photographic photometry, indicate the depolarisation of this line with a fine slit to be 18 per cent. Manneback's theory indicates that the depolarisation should increase, when a very wide slit is used, to 44 per cent, while the theory of spinning photons gives it as 26 per cent. The latter is in close agreement with the observed value, which is 25 per cent.

It is well known that some vibrational Raman lines show very large depolarisation. Bär ${ }^{3}$ and Hanle have observed that such lines exhibit the phenomenon of reversal of circular polarisation. In terms of the theory of photon spin, we must assume that in such cases the molecule takes up angular momentum from the incident light in some manner otherwise than by its rotation as a complete entity. Internal spins or rotations within the molecule associated with such modes of vibration have to be postulated. The familiar example of a vibrating string or rod which describes circles or ellipses may help in picturing this state of affairs.

210 Bowbazar Street, Calcutta,

\section{S. Bhagavantam.} Dec. 13.

1 Ind. J. Phys., vol. 6, p. 353; 1931.

Z. Phys, vol. 62 , p. $224 ; 1930$.

Helv. Phys. Acta, vol, 4, p. $130 ; 1931$

4 Naturwiss., vol. 19, p. $375 ; 1931$.

\section{Behaviour of Pyroelectric Crystals.}

IN some simple demonstration experiments using liquid air we repeated many of the interesting observations reported by $\mathrm{L}$. Bleekrode ${ }^{1}$ and by Miss M. E. Maurice $^{2}$ on the demonstration of electric lines of foree around pyroelectric crystals. As these papers may have escaped the notice of some mineralogists and crystallographers, we feel it may be helpful to direct attention to what, in our estimate, is the simplest and most striking way of demonstrating the phenomenon of pyroelectricity.

As it came to our notice that at least some minera. logists have considerable difficulty in showing this phenomenon by the well-known method due to Kundt, which consists in dusting finely pulverised red lead and sulphur over the crystal as it cools, we employed this process, taking all the precautions mentioned by Dana ${ }^{3}$ to ensure success. Although Dana refers to this method as "very convenient and simple", we consider that Bleekrode's method, in which the low temperature of liquid air is utilised, has advantages over it in this respect. Further, our experiments, using Kundt's method, did not show the effects predicted at all clearly; in fact, we obtained convincing results only in certain simple cases, for example, with a long tourmaline crystal possessing one polar axis.

In contrast to this, the behaviour of a crystal after immersing it in liquid air leaves no doubt as to its pyroelectric nature. The directed growth of the whisker-like ice filaments which form on the polar surfaces of pyroelectric crystals as they warm in air is striking, especially when viewed through a lowpower microscope. The shooting off of portions of the ice filaments along the lines of electric force is most marked about a minute after these crystals begin to form. Although we observed the phenomenon clearly with tourmaline and quartz, it was best shown by a small boracite crystal with cubic, rhombic, dodecahedral, and positive and negative tetrahedral faces. Clouds of small ice projectiles passed during a limited period between one set of tetrahedral faces possessing a positive charge and the other negatively charged set. Even with a tourmaline crystal about $4 \mathrm{~cm}$. long, small particles were shot from one pole to the other. By means of an electrified rod, it was easy to show the nature of the poles with this crystal.

In her paper (loc. cit.) Miss Maurice described a new method for measuring the electric moment of a tourmaline crystal, in which the crystal was deflected by an electric doublet. We made an approximate determination of this quantity simply, by suspending the crystal from a single silk thread and then determining its period of vibration in the uniform electric field existing between two large parallel plates in air. In two successive trials the electric moment obtained was $31.3,31.6$ e.s.u. and the charge on each end $11 \cdot 2,11 \cdot 3$ e.s.u., the crystal having cooled after being discharged in each case through about $150^{\circ} \mathrm{C}$. The minimum period occurred after twenty minutes' cooling, and it was used in the calculation. As no special precautions were taken to prevent leakage from the crystal, the absolute values have little significance.

My thanks are due to Mr. C. A. Jarman for assistance with these experiments, and to Prof. W. N. Benson, who lent the crystals.

Physics Department,

Charles M. Focken.

University of Otago, N.Z.

L. Bleekrode, Ann. Phys., 12, p. $218 ; 1902$.
2 Miss M. E. Maurice, Proc. Camb. Phil. Soc., 26, part iv., p. 491; 1930 .

${ }_{3}^{3}$ E. S. Dana, “A Text-Book of Mineralogy", 3rd edition, p. 307.

Microscopic Cracks produced by Electric Spark.

IF a thick electric spark is made to glide along the surface of a piece of an ordinary window glass, a faint trace of the spark track is left on the glass surface. On examining this track under microscope, we find a large number of hair-like cracks running

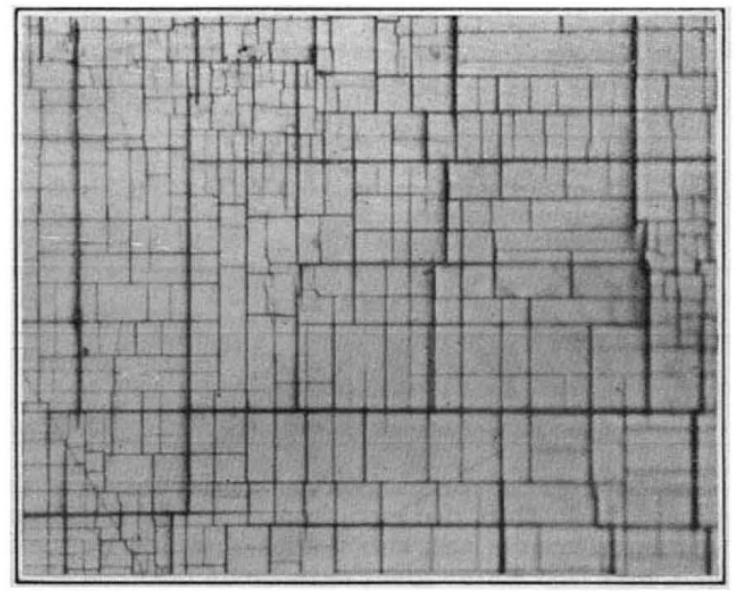

Fia. 1.-Cracks on a cleavage surface of rock salt crystal produced by repeated sparking. Spark length, $3 \mathrm{~cm}$; capacity, $15 \mathrm{~m}$. $\times 150$.

roughly parallel to each other and transverse to the axis of the track. It is interesting to observe that the cracks undergo further development even if left undisturbed. Minor secondary cracks gradually appear, filling up the space between the primary cracks with complicated networks. A thin surface layer bounded by these cracks begins to be peeled off, showing thus a mozaic of Newton rings. This latter pattern becomes visible an hour after the sparking and is most marked along the middle zone of the track.

No. 3248, VoL. 129] 